\title{
Ozone Effects on Fruit Productivity and Photosynthetic Response of Two Tomato Cultivars in Relation to Stomatal Fluxes
}

\author{
Giacomo Gerosa ${ }^{1 *}$, Riccardo Marzuoli ${ }^{1}$, Angelo Finco ${ }^{1}$, Andrea Ebone ${ }^{2}$, \\ Francesco Tagliaferro ${ }^{2}$ \\ ${ }^{1}$ Università Cattolica di Brescia \\ Via dei Musei 41 - 25121 Brescia, Italy \\ ${ }^{2}$ Istituto per le Piante da Legno e l'Ambiente - IPLA \\ Corso Casale 476, 10132 Torino, Italy
}

Received: 4 February 2007. Accepted 15 February 2008.

\begin{abstract}
An Open-Top Chamber experiment on two tomato cultivars (cv. Oxheart and cv. San Marzano) was carried out in Curno (Northern Italy) between June and September 2007. Two ozone treatments were applied for a 3.5 months period: Non-Filtered OTC (NF-OTC, $95 \%$ of ambient ozone) and Charcoal-Filtered OTC (CF-OTC, $50 \%$ of ambient ozone). Diurnal cycles of porometry measurements were performed during the season and allowed to draw a stomatal conductance model for each cultivar in order to calculate the ozone stomatal fluxes taken up by plants. Assessments on fruits yield were performed during the season, taking into account the number of fruits, their fresh weight and their marketability. In addition, measurements on the chlorophyll fluorescence of photosystems were carried out to assess possible negative effects on photosynthetic efficiency. Despite the two cultivars absorbed a similar ozone stomatal dose during the season (with an $8 \%$ difference), their responses to ozone treatments were totally divergent in relation to both fruits yield and photosynthetic efficiency. Plants of cv. Oxheart grown in NF-OTCs showed significant yield loss in the total weight of fruits $(-35.9 \%)$ which is exclusively related to a decrease in the number of fruits produced $(-35.7 \%$ of total fruits; $-30.6 \%$ of marketable fruits), since mean fresh weight of fruits remained unaffected. Moreover the same plants displayed low values (in comparison to CF-OTCs plants) of the photosynthetic efficiency index $\left(\mathrm{PI}_{\text {abs }}\right.$ ) during the most intense period of ozone stress (July) occurred in the flowering stage of plants and at the beginning of fructification. Plants of the cv. San Marzano had an opposite response behaviour with an increase of the mean fresh weight of fruits in plants grown in NF-OTC (even if not statistically significant) and no difference in the number of fruits produced and in the values of photosynthetic efficiency.
\end{abstract}

Key-words: tomato, ozone fluxes, stomatal conductance, marketable fruits, chlorophyll fluorescence.

\section{Introduction}

Tropospheric ozone pollution is known to be an important risk factor causing negative impacts on crop yield in many parts of Europe and North America (Benton et al., 2000; Mauzerall and Wang, 2001; Pleijel et al., 2007). A constant increase of ozone concentration background levels has been recorded during the last decades in the most industrialized countries, particularly in the Mediterranean area, as a consequence of increasing emissions of anthropogenic precursors (Vingarzan, 2004; EEA, 2007). Starting from the 80s, many experimental studies and International research programs have tried to assess ozone negative effects on vegetation and concluded that this pollutant is the main responsible of ecological and economical damages on crops, forests and semi-natural vegetation in almost every European and North-American Country (Fuhrer et al., 1997; UN/ECE, 2004) and in many developing Countries (Emberson et al., 2001).

Moreover, several investigations have repeatedly shown that ozone impact is more strict-

* ?Corresponding Author: Tel.: +39 030 2406719; Fax: +39 030 2406742. E-mail: giacomo.gerosa@unicatt.it 
ly linked to the ozone flux truly absorbed by plants through stomata rather than to the mere exposure to a given air concentration (Musselman and Massman, 1999; UN/ECE, 2004).

As a consequence, a large effort of the scientific community is aimed to the development of stomatal conductance models suitable for ozone-flux calculation or estimation, and to the definition of reliable ozone-flux response relationships for large scale risk assessments. Currently, this kind of relationships has been developed for wheat and potato grown in Northern Europe climatic conditions, since these crops have the major datasets available (Pleijel et al., 2002; Danielsson et al., 2003).

On the contrary, relatively few datasets are available from southern Europe, which can be used to derive ozone-flux relationships for the main sensitive Mediterranean crops (e.g. fieldgrown horticultural crops such as tomato, lettuce, spring onion and soft fruit), and the most recent Mapping Manual from UN/ECE (2004) still suggests to use a concentration-based critical level for horticultural crops calculated over a 3.5 months period. Moreover, Mediterranean Countries, and particularly Italy, show the highest ozone concentrations in Europe, due to the high levels of temperature and solar radiation during summer (EEA, 2006; Paoletti, 2006).

Given these preliminary remarks, the objective of the present study was to evaluate the negative effects of ozone on crop yield, assessed as relative biomass reduction in ripe fruits, of two well-spread cultivars of tomato (Lycopersicon esculentum Mill., cv. "Hoxheart" and cv. "San Marzano") in relation to ozone exposure and ozone uptake as stomatal fluxes. Furthermore, a possible effect on the performance of the photosynthetic systems has been investigated with measurements on the fluorescence transient of the chlorophyll $a$ in photosytems II.

Italy is the European country leader in the annual production of tomatoes with $6.3 \mathrm{M}$ of tonnes and 122,000 ha of cultivated areas in 2006 (FAOSTAT, 2007), and with $2 / 3$ of this production deriving from open-field cultivations; it is thus obvious that the assessment of a significant yield loss due to the high ambient levels of ozone may have important impacts and consequences also from an economical point of view.

Data reported from this experiment can be considered as a contribution for the definition of an appropriate ozone flux-based critical level for the most sensitive horticultural crops at European level. Such critical level will take into account all the environmental conditions that influence stomatal conductance, and yield losses related to the ozone uptake.

\section{Materials and methods}

The experiment was carried out in summer 2007 in the Open-Top Chambers (OTC) research site of Curno Forest Nursery (lat. 45 $70^{\prime}$ N, long. $9^{\circ} 62^{\prime} \mathrm{E}$, elev. $242 \mathrm{~m}$ asl) on the Northern edge of the Po Valley. Details concerning the construction parameters of the OTCs and the pollution conditions of the area have been reported in previous studies (Bussotti et al., 2007a, Gerosa et al., 2007). Experiments were made with two cultivars of Lycopersicon esculentum Mill., cv. Oxheart and cv. San Marzano, using four OTCs and two ozone exposure treatments: $50 \%$ ambient ozone in charcoal-filtered OTC (CF), 95\% ambient ozone in non-filtered OTC (NF). Plants were transplanted on May 17 in single pots filled with a standard peat based substrate, and placed inside the OTCs from June 1 until September 15, when ripe fruits harvest was concluded. Five plants for each cultivar were grown in each OTC and optimal conditions of irrigation were maintained throughout the whole experiment period.

Ozone concentrations within each chamber were continuously monitored with an ozone automatic analyzer model 1308 RS (Dasibi Italia srl, Milano, I), via a solenoid valves switch system, which drew air through sampling points at the centre of each chamber at $90 \mathrm{~cm}$ a.g.l. The system was driven and controlled by a personal computer equipped with an NI-DAQ 6.9 I/O board and a Labview 6.1 program (National Instruments, Austin, Texas), purposely devised. Temperature and relative humidity were monitored in one filtered OTC using a Vaisala 50Y sensor (Vaisala, Vantaa, Finland). At the same time, all relevant meteorological data from a two-level tower ( $3 \mathrm{~m}$ and $6 \mathrm{~m}$ ) were continuously monitored and recorded by a CR10X datalogger (Campbell Sci., Logan, Utah) equipped with an AM16/32 relay multiplexer and an SDM-SW8A switch closure interface (Campbell Sci., Logan, Utah). 


\subsection{Stomatal conductance measurements and modelling}

Stomatal conductance to water vapour $\left(\mathrm{g}_{\mathrm{W}}\right)$ was measured with a cycling diffusive porometer AP-4 (Delta-T Devices LTD, Cambridge, UK). The instrument works by measuring the time it takes for a leaf to release sufficient water vapour to change the relative humidity in a small chamber by a fixed amount. This is compared with a calibration plate of known resistance in order to derive the stomatal resistance or conductance of the leaf. The instrument was calibrated before each series of measurements. Measurements were performed on five different days from July 17 to September 5, with four diurnal cycles starting from 8:00 AM until 5:30 PM. Leaf stomatal conductance was measured in the median portion of the lamina, on one light-exposed leaf of each plant in all the OTCs.

In order to calculate stomatal fluxes, the stomatal conductance for each species has been modelled using the classical Jarvis multiplicative approach (Jarvis, 1976):

$$
\mathrm{g}_{\mathrm{w}}=\mathrm{g}_{\max } *\left[\mathrm{f}_{\mathrm{T}} * \mathrm{f}_{\mathrm{PAR}} * \mathrm{f}_{\mathrm{VPD}}\right]
$$

The $\mathrm{g}_{\max }$ for water value has been chosen by taking the $95^{\text {th }}$ percentile of all the valid stomatal conductance measurements.

The limiting functions $\mathrm{f}_{\mathrm{T}}, \mathrm{f}_{\mathrm{PAR}}, \mathrm{f}_{\mathrm{VPD}}$, which give a value between 0 and 1 , were characterized by borderline analysis, using the points corresponding to the $98^{\text {th }}$ percentile of $g_{\text {rel }}$ (conductance value relative to the $\mathrm{g}_{\max }$ ) plotted for each class of values of environmental variable considered (T, VPD, PAR). It was thus possible to make the modelling less dependent on outliers representing measurements of doubtful quality. No limiting function for soil water content was considered because constant irrigation was provided during the whole season (pots were irrigated every two days).

\subsection{Calculation of ozone stomatal fluxes and ozone exposure}

Ozone stomatal fluxes were calculated for a top canopy leaf according to Emberson et al. (2000) and Karlsson et al. (2000):

$$
F_{s t, 03}=\left[\mathrm{O}_{3}\right] /\left(R_{b, 03}+1.68 / g_{w}\right)
$$

where 1.68 accounts for the different diffusivity of water in air with respect to the ozone. The sub-laminar ozone resistance $R_{b, O 3}$ was obtained using Unsworth (1984) equation:

$$
R_{b, O 3}=k *(d / u)^{1 / 2}
$$

where the empirical coefficient $k$ is set to a value of 132, as supported by Thom's 1975 measurements, $d$ is the mean leaf width for each specie, and $u$ is the mean wind speed at top canopy level.

Ozone dose was calculated summing up all the semi-hourly stomatal fluxes from June 1 , when pots were placed in OTCs, to September 15 when the experiment was concluded. In the same period of 3.5 months, as suggested by UN/ECE (2004), ozone exposure during daylight hours was calculated by means of the AOT40 index (Kärenlampi and Skärby, 1996).

\subsection{Chlorophyll a fluorescence measurements}

Photosynthesis parameters were measured on 17 and 24 July, 2 and 13 August and 5 September. All measurements were performed with a HandyPEA fluorimeter (Hansatech Instruments, Norfolk, UK) between 10 and 11 AM (in order to avoid the hottest hours in the summer) on two leaves, chosen at random, for each individual. Measurements were taken in subapical position and with a good exposure to light. Before each measurement, the leaves were dark adapted for $30 \mathrm{~min}$ with leaf clips. The rising transients were induced by a red light (peak at $650 \mathrm{~nm}$ ) of $600 \mathrm{Wm}^{-2}$ provided by an array three light-emitting diodes. Data recorded and JIPtest parameters (Strasser et al., 2000; Strasser et al., 2004) were processed through Biolyzer 3.0 software (by Ronald M. Rodriguez, Bioenergetics Laboratory, Geneva, $\mathrm{CH}$ ).

\subsection{Fruits yield assessment}

Tomato fruits were weekly harvested, starting from July 28, until the end of experiment (September 15). For each plant, fruits were counted, weighed and ranked for their marketability. Ripe fruits with visible lesions and/or having weight $<10 \mathrm{~g}$ were considered non-marketable. Data for each cultivar and ozone treatment were analyzed by one-way ANOVA for a completely randomized design. 


\section{Results}

\subsection{Meteorological conditions and ozone expo- sure}

Trends and mean values of the main meteorological parameters, during the 3.5 months experiment period, are reported in figure 1 and table 1. For a large part of this period daily mean temperatures were between 20 and $25^{\circ} \mathrm{C}$, with the exception of the last two weeks of July, characterized by sunny warm and dry conditions and by daily mean temperatures slightly below $30{ }^{\circ} \mathrm{C}$. Seasonal rainfalls (Tab. 1) were mostly concentrated in August $(142 \mathrm{~mm})$ with highly dry conditions in June $(21 \mathrm{~mm})$ and typical values in July $(73 \mathrm{~mm}$, occurred during the first days of the month).

Table 1 reports also, for each month, mean concentrations of ozone, maximum values registered and AOT40 values in the two ozone treatments (NF-OTC and CF-OTC). It is evident that during July, warm and dry conditions (and low rainfalls) strongly enhanced the photochemical processes that lead to the formation of tropospheric ozone, which maintained a monthly concentration average higher than the phytotoxic threshold (40 ppb) and an AOT40 monthly value corresponding to the $60 \%$ of the total seasonal value. In figure 2 we reported the seasonal trend of AOT40 index confronting the two different ozone treatments used. In the NFOTCs, the final value of AOT40 was $8162 \mathrm{ppb}$ $\mathrm{h}$, far beyond the concentration-based critical level of 6000 ppb.h suggested by UN/ECE (2004), which was reached on August 5. In the CF-OTCs on the contrary, the AOT40 index was below $1000 \mathrm{ppb}$ h, thanks to a good performance of the charcoal filters (Fig. 3). Seasonal curve in the NF-OTCs displays a sigmoidal course with a large part of accumulation concentrated between the first days of July and the middle days of August.

\subsection{Stomatal conductance model and ozone fluxes}

A database of 700 measurements of abaxial surface stomatal conductance to water vapour was used to draw two stomatal conductance models, one for each cultivar. The maximum stomatal conductances $\left(\mathrm{g}_{\max }\right)$ individuated for the two cultivars are reported in table 2 (values are re-

Table 1 . Monthly average values for the main meteorological and ozone parameters.

\begin{tabular}{lcccccrr}
\hline & T $\left({ }^{\circ} \mathrm{C}\right)$ & UR $(\%)$ & $\begin{array}{c}\text { Rain } \\
(\mathrm{mm})\end{array}$ & $\begin{array}{c}\text { Mean O3 } \\
\text { ppb* }^{*}\end{array}$ & Max O3* & $\begin{array}{r}\text { AOT40 } \\
\text { NF ppb.h }\end{array}$ & $\begin{array}{c}\text { AOT40 } \\
\text { CF ppb.h }\end{array}$ \\
\hline June & 21.9 & 64.6 & 21 & 23.9 & 58.0 & 374 & 23 \\
July & 25.2 & 44.5 & 73 & 43.5 & 104.0 & 4952 & 708 \\
August & 22.7 & 61.2 & 142 & 33.2 & 79.0 & 2401 & 193 \\
September** & 20.4 & 51.5 & 0 & 25.7 & 69.0 & 435 & 0 \\
\hline
\end{tabular}

* Values reported are from ozone sampling points of Non-Filtered OTC.

** Values calculated only for the first 15 days of the month.

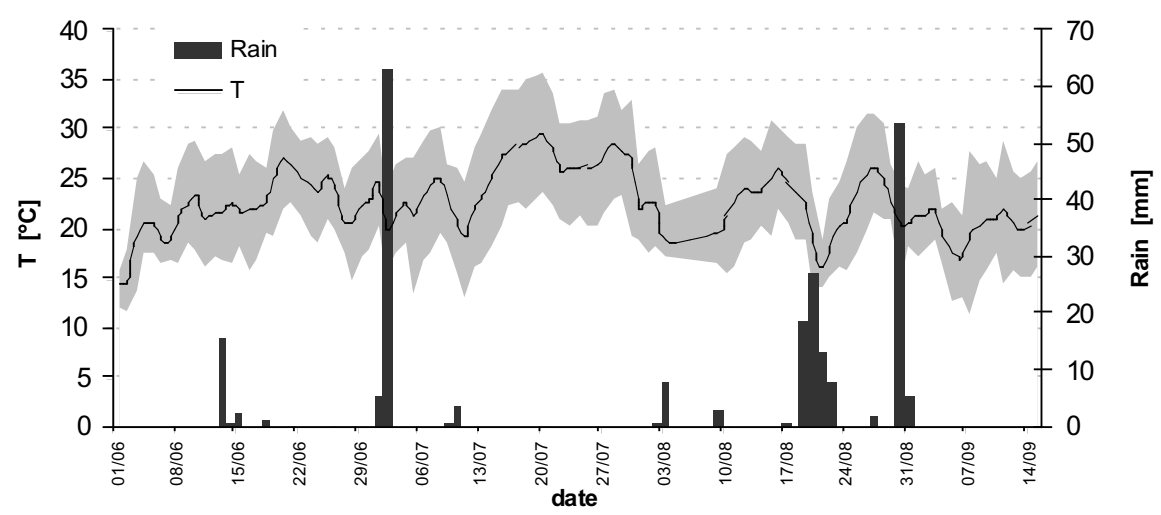

Figure 1 . Daily mean temperature and rain during the experiment period. Grey area is delimited by maximum and minimum daily temperature. 


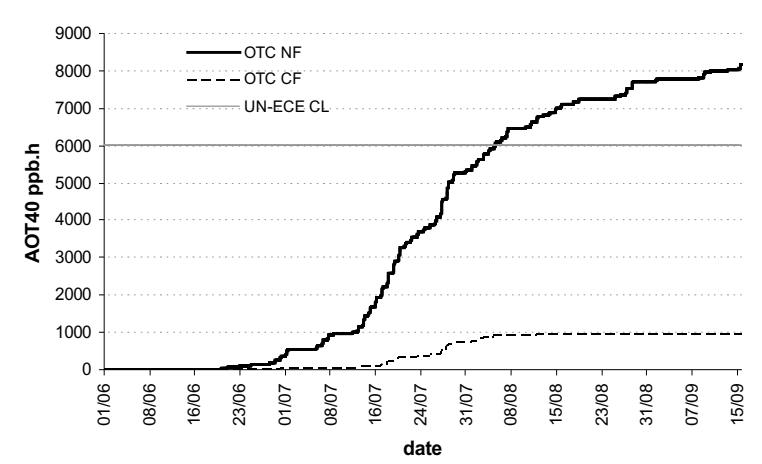

Figure 2. AOT40 index during the growth season in Charcoal Filtered (CF) and Non-Filtered (NF) Chambers. Grey line is the UN-ECE Critical Level (CL) for tomato.

ferred to Projected Leaf Area). Table 2 also reports the equations of the limiting functions $\mathrm{f}_{\text {PAR }}, \mathrm{f}_{\mathrm{T}}, \mathrm{f}_{\mathrm{VPD}}$ and the values of their parameters obtained by the boundary-line analysis (Fig. 4). These models were "fed" with the meteorological parameters referred to the top canopy leaves in order to calculate the cumulative ozone stomatal fluxes $\left(\mathrm{AF}_{\mathrm{ST}}\right)$ reported in figure 5. Despite a $22 \%$ difference in the $\mathrm{g}_{\max }$ values of the two cultivars, the seasonal ozone stomatal doses were quite similar: 39.66 and 36.63 $\mathrm{mmolm}^{-2} \mathrm{~s}^{-1}$ in NF-OTCs, respectively for $\mathrm{cv}$. Oxheart and cv. San Marzano, 20.57 and 19.84 in CF-OTCs.

The general trend of the $\mathrm{AF}_{\mathrm{ST}}$ during the season was significantly different from the AOT40 trend reported in figure 3 being more regular with a quite constant increasing in both treatments.

\subsection{Fruits yield}

The total and commercial yields, expressed as fresh weight of ripe fruits, were significantly affected by ozone treatment only in cv. Oxheart (Tab. 3). Plants of this cultivar grown in NFOTCs show large decrease in fresh weight values of total fruits and marketable fruits, with significant differences in comparison to the plants grown in CF-OTCs $(-35.9 \%$ and $-30.87 \%$ respectively). The reduced yield was mainly caused by a reduction in fruits number rather than fruits mean fresh weight, which remained totally unaffected $(-0.33 \%)$. The percentage of non-commercial fruits was approximately $17 \%$ and $7 \%$ of the total fruits harvested respectively in CF-OTCs and NF-OTCs.

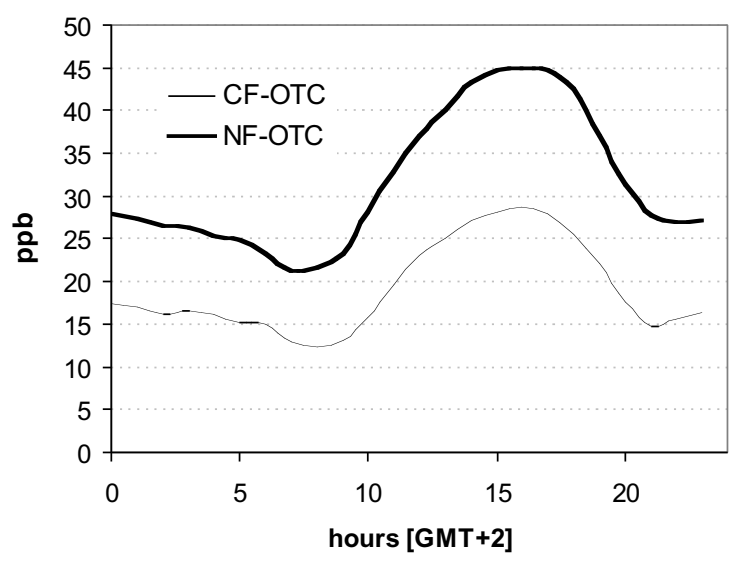

Figure 3. Mean daily ozone concentration in Charcoal-Filtered OTCs (CF-OTC) and in Non-Filtered OTCs (NFOTC) during the growing season (1 June - 15 September).

Table 2. Summary of the coefficients values for the stomatal conductance models of the two tomato cultivars.

\begin{tabular}{|c|c|c|c|c|}
\hline Equation function & Parameter & Oxheart & San Marzano & Unit \\
\hline & $\begin{array}{c}g_{\max } \\
(P . L . A .)\end{array}$ & 1.425 & 1.825 & $\mathrm{~cm} / \mathrm{s}$ \\
\hline$f_{P A R}=1-e^{-a \cdot P A R}$ & $a$ & 0.020 & 0.025 & adim. \\
\hline $\begin{array}{r}f_{T}=\frac{\left(T-T_{\min }\right)}{\left(T_{o p t}-T_{\min }\right)} \cdot\left[\frac{\left(T_{\max }-T\right)}{\left(T_{\max }-T_{o p t}\right)}\right]^{b} \\
f_{V P D}=\frac{(1-0.1) \cdot(c-V P D)}{(c-d)}+0.1\end{array}$ & $\begin{array}{l}T_{o p t} \\
T_{\max } \\
T_{\min } \\
b \\
c \\
d\end{array}$ & $\begin{array}{c}27 \\
39 \\
13 \\
0.857 \\
5.53 \\
1.8\end{array}$ & $\begin{array}{c}27 \\
37 \\
15 \\
0.833 \\
3.87 \\
1.25\end{array}$ & $\begin{array}{c}{ }^{\circ} \mathrm{C} \\
{ }^{\circ} \mathrm{C} \\
{ }^{\circ} \mathrm{C} \\
\text { adim. } \\
\mathrm{KPa} \\
\mathrm{KPa}\end{array}$ \\
\hline
\end{tabular}

Notes: $P A R$ is the photosintetically active radiation expressed as $\mu \mathrm{mol}_{\text {photons }} \mathrm{m}^{-2} \mathrm{~s}^{-1} ; T_{\min }$ and $T_{\max }$ are the range of temperature where the stomatal conductance is above its minimum value, and $T_{\text {opt }}$ is the temperature where $g$ reaches $g_{\max }$, with all the temperatures expressed in ${ }^{\circ} \mathrm{C} ; V P D$ is the atmospheric water vapour pressure deficit expressed in $\mathrm{KPa}$. 
cv. "Oxheart"

a)

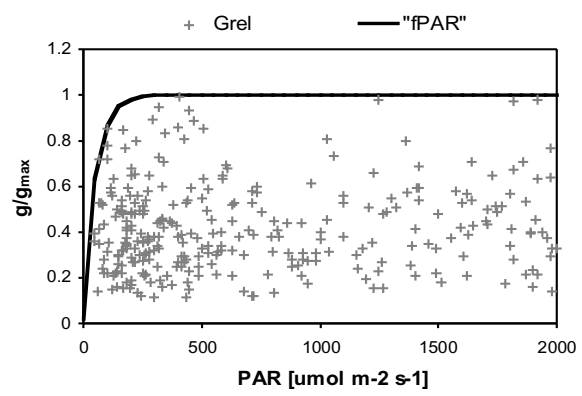

c)

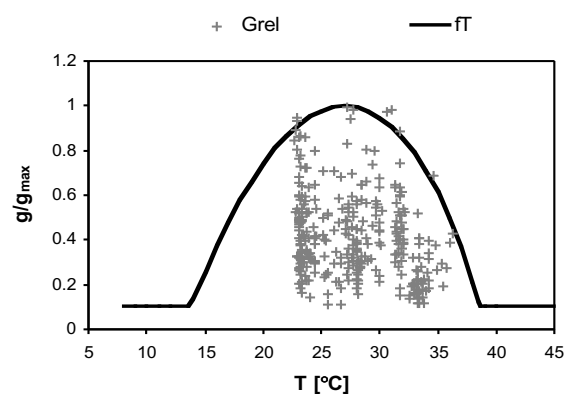

e)

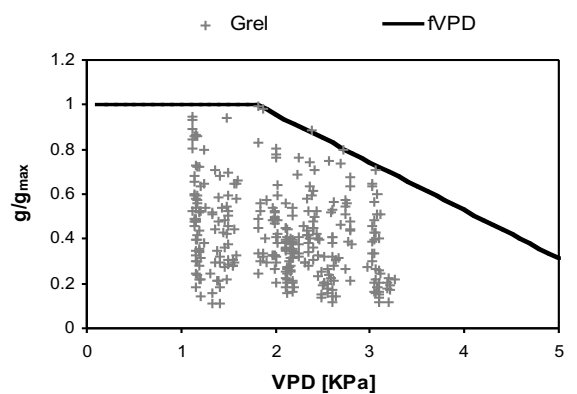

cv. "S. Marzano"

b)

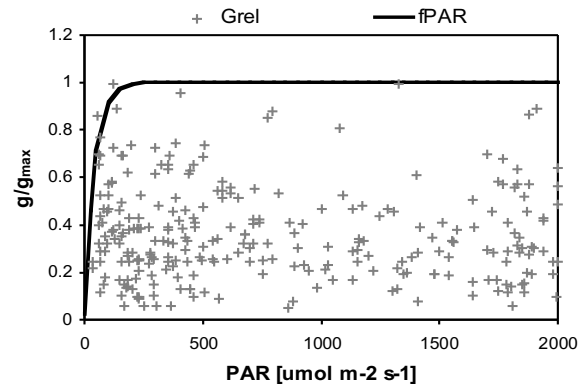

d)

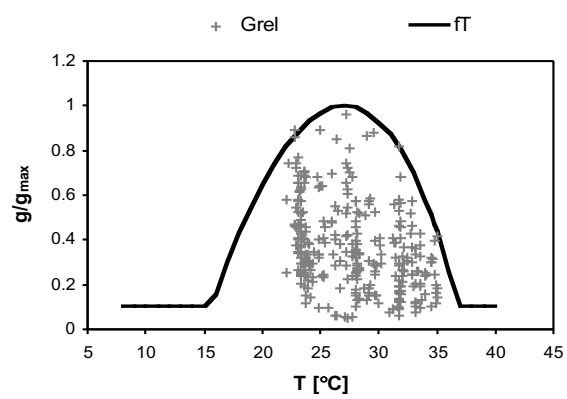

f)

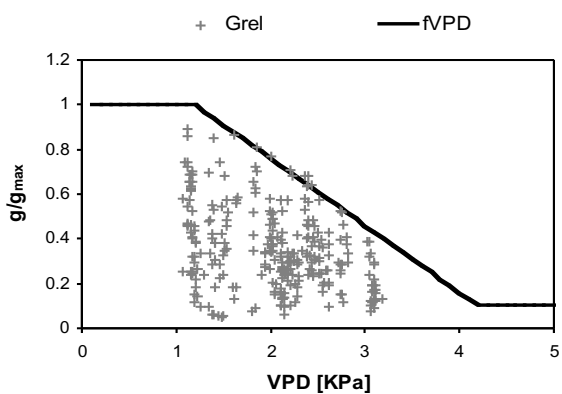

Figure 4. The $f$ functions for the stomatal conductance models indentified by boundary line analysis. Figures a), c) and e) refers to the "Oxheart" cultivar, while b), d), f) to the cultivar "S. Marzano". $f P A R, f T$ and $f V P D$ describes the dependence of the stomatal conductance to light, temperature and air vapour pressure deficit, respectively.

On the contrary, fruits yield in cv. San Marzano displayed opposite results in comparison to Oxheart. Plants grown in NF-OTC show an increase in total yield and marketable yield respectively of $20.46 \%$ and $28.21 \%$. These differences were related to the mean fresh weight of fruits $(+29.15 \%$ in NF-OTC) rather than the fruits number which remained substantially identical (-0.74\% for marketable fruits).

\subsection{Photosynthetic efficiency}

Data from the five measurement campaigns carried out during the experiment were analysed and screened by ANOVA for repeated mea-

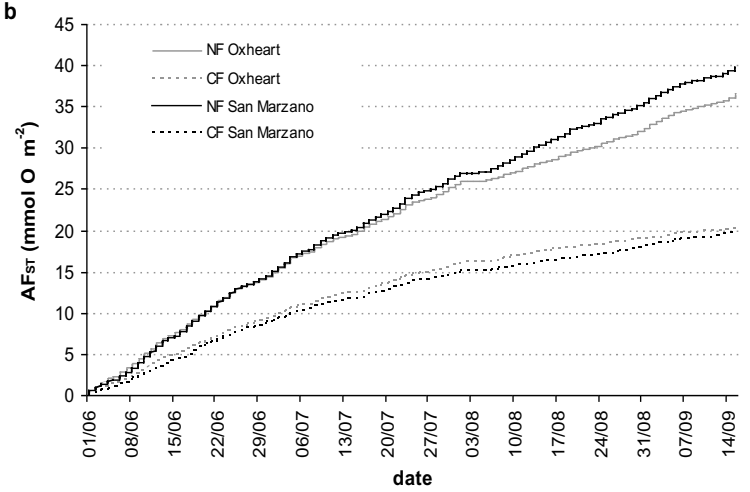

Figure 5. Accumulated stomatal fluxes $\left(\mathrm{AF}_{\mathrm{ST}}\right)$ during the growing season in Charcoal Filtered (CF) and Non-Filtered (NF) OTCs for the two tomato cultivars. 
Table 3. Fruits yield for the two tomato cultivars in the Charcoal-Filtered (CF) and Non-Filtered ozone treatments.

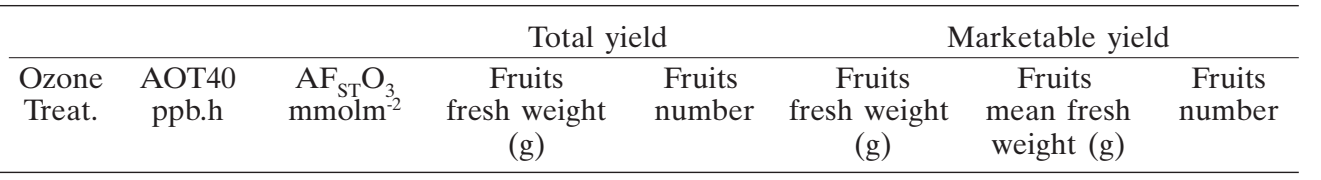

\begin{tabular}{lrrrrrrrr}
\hline Oxheart & & & & & & & & \\
& CF & 924 & 20.57 & 10333.0 & 90 & 8968.6 & 119.6 & 75 \\
Difference & NF & 8162 & 36.63 & 6621.6 & 56 & 6199.6 & 119.2 & 52 \\
\hline San Marzano & & & & $-35.90 \% *$ & $-37.77 *$ & $-30.87 \% * *$ & $-0.33 \%$ & $-30.66 \%$ \\
& CF & 924 & 19.84 & 4734.2 & 187 & 3955.2 & 29.5 & 134 \\
& NF & 8162 & 39.66 & 5703.2 & 169 & 5071,0 & 38.1 & 133 \\
Difference & & & & $+20.46 \%$ & $-9.62 \%$ & $+28.21 \%$ & $+29.15 \%$ & $-0.74 \%$ \\
\hline
\end{tabular}

$* \mathrm{p}<0.1$.

$* * \mathrm{p}<0.05$.

surements. However scarce significance in the differences between the two ozone treatments was found for the main fluorescence parameters usually assessed, as $\mathrm{Fv} / \mathrm{Fm}, \mathrm{Kp}$ and $\mathrm{Kn}$.

Figure 6 reports the ratio NF/CF for the Performance Index based on absorption ( $\mathrm{PI}_{\mathrm{abs}}$, Clark et al., 2000) which expresses the overall photosynthetic efficiency of the plant. Plants of cv. Oxheart grown in NF-OTCs had low values of $\mathrm{PI}_{\mathrm{abs}}$ in the first three measurement campaigns, between July 17 and August 3, and presented a large increasing in the last two campaigns, strongly exceeding the CF plants values. In the same figure are also reported the hourly means of ozone concentration for the time period during which fluorescence measurements were performed. The first three measurement assessments were carried out during a long period of high ozone concentrations that began to decrease after the first days of August.

Plants of cv. San Marzano on the contrary show, for the two ozone treatments, quite identical values during the whole season with a slight difference only in the first assessment (July 17), when NF plants had a higher level of photosynthetic efficiency than CF plants.

\section{Discussion}

The two stomatal conductance models showed fairly high values of $g_{\max }$, but it should be noted that in our experiment $\mathrm{g}_{\max }$ was determined on measurements carried out on plants grown in conditions of maximum conductibility (i.e. non-limiting water supply), and this definitively contributed to the high values. Nevertheless, these values can be considered consistent with other studies on tomato carried out with the same instrument (Sobeih et al., 2004) in nonlimiting water conditions.

A negative impact of ozone on fruits yield of cv. Oxheart was clearly detected and related to a reduction in the number of fruits produced rather than the mean fresh weight. This latter parameter was not affected by ozone treatment, thus indicating that once the fructification process has started it is regularly carried on and concluded. The reduction in the total number of ripe fruits is also consistent with other results obtained for watermelon (Gimeno et al., 1999), beans (Schenone et al., 1992; Gerosa et al., submitted) and cucumber (Khan and Khan, 1999) and there is evidence that crop yield responses to ozone exposure are growth-stage dependent (Younglove et al., 1994; Stewart et al., 1996; Drogoudi and Ashmore, 2000). In this case it can be hypothesized the existence of an adverse effect of ozone on flowering or a higher susceptibility of plants during the period between flowering and fruit set, as suggested by other authors (Younglove et al., 1994; Calvo et al., 2007). Moreover in the same period the Performance Index $\left(\mathrm{PI}_{\mathrm{abs}}\right)$ of NF-OTC plants displayed lower values in comparison to CF-OTCs plants (Fig. 6) and high levels of ozone concentration have been monitored in July, during the flowering stage of plants and at the beginning of fructification (the first harvest was on July 
28). This decrease in the photosynthetic efficiency indicates a stress condition not adequately contrasted by the metabolic defence system at cellular and physiological level, and reveals negative effects of ozone directly on the photosynthetic processes, as suggested by other studies (Heath, 1994; Schraudner et al., 1997; Calatayud and Barreno, 2001; Degl'Innocenti et al., 2002). These impacts lead to a decrease of the energy available for flowering thus determining a decrease in the number of fruits.

On the contrary the San Marzano cultivar did not show ozone negative effects on fruit yield (both total and commercial) but a possible stimulating effect was detected, even if not statistically significant. In fact the NF-OTC plants of this cultivar showed a better photosynthetic efficiency, revealed by higher $\mathrm{PI}_{\mathrm{abs}}$ relative values, than the CF-OTC plants starting already from the first assessment till the end of the season. The increase in photosynthetic efficiency as a response to oxidative stress has been already described by other authors (see e.g. the review of Bussotti et al., 2007b) and may generally enable the plants to respond to the need of metabolites, in order to feed the acclimatization process (detoxification and repair).

In many studies different responses to ozone have been explained by differences in stomatal conductance, and thus by the different ozone dose taken up by plants (Beyers et al., 1992; Panek and Goldstein, 2001; Fagnano and Merola, 2007; Gerosa et al., 2007). In this case, however, the different response of the two cultivars should be attributed to a genetically different sensitivity to ozone, since the cumulative stomatal ozone uptakes (AFst) were quite identical at the end of the season. Moreover the seasonal trends of ozone uptake were practically identical, thus excluding an effect of different timing in ozone dose accumulation. A seasonal difference of $8 \%$ in stomatal fluxes seems too low to explain such divergent responses in fruits yield.

The ozone tolerance of cv. San Marzano suggests a more efficient detoxification system at cellular level of this cultivar with respect to the other, which allows these plants to contrast the oxidative stress. The resistance to ozone has been often associated to high levels of antioxidants enzymes and compounds in the apoplast and the cytoplasm of foliar cells and to the ca- pacity of plants to increase the activity of such metabolic defence under oxidative stress (Kangasjarvi et al., 1994; Ranieri et al., 1996; Rabotti and Ballarin-Denti, 1998; Langebartels et al., 2002; Maggio et al., 2007). The cv. San Marzano, that is a pool of ecotypes selected in Campania Region in $30 \mathrm{~s}$, seems to be more adapted to warm climates in which high temperature and sun radiation are frequently occurring with high ozone concentrations, as typical of Mediterranean area and particularly in Southern Italy.

\section{Conclusions}

Tomato cv. Oxheart is sensitive to ozone in relation to fruits yield while cv. San Marzano does not show particular susceptibility to this pollutant. Ozone impacts on cv. Oxheart affects the number of fruits (both total and marketable) rather than the size and the mean weight of fruit. Yield losses seem related to negative effects on photosynthetic efficiency occurring during flowering process and immediately before fructification. Quantification of fruits yield losses and calculation of cumulated ozone fluxes during the growing season, together with analogous results from other countries, may contribute to the definition of an appropriate flux-based critical level for horticultural crops. However results from this experiment give evidence that intraspecific variability of response to ozone can be as important as interspecific variability.

\section{Acknowledgements}

The OTC research site of Curno (CRINES), where this work was carried out, have been established and funded from Regione Lombardia, involving the Regional Agency for Services to Agriculture and Forests - ERSAF - and the Lombardy Foundation for Environment (FLA) The authors are grateful to the ERSAF personnel for their valuable assistance at the Curno forest nursery and to IPLA (Istituto per le Piante da Legno e l'Ambiente, Regione Piemonte) for providing plant material.

\section{References}

Ashmore M. 2005. Assessing the future global impacts of ozone on vegetation. Plant Cell Environment, 28:949-964.

Benton J., Fuhrer J., Gimeno B.S., Skärby L., PalmerBrown D., Ball G.R., Roadknight C., Mills G. 2000. 
An international cooperative programme indicates the widespread occurrence of ozone injury on crops. Agriculture Ecosystem Environment, 78:19-30.

Beyers J.L., Riechers G.H., Temple P.J. 1992. Effects of Long-Term Ozone Exposure and Drought on the Photosynthetic Capacity of Ponderosa Pine (Pinus ponderosa Laws.). New Phytologist, 122:81-90.

Bussotti F., Desotgiu R., Cascio C., Strasser R.J., Gerosa G., Marzuoli R. 2007a. Photosynthesis responses to ozone in young trees of three species with different sensitivities, in a two-year open-top chamber experiment (Curno, Italy). Physiologia Plantarum, 130:122-135.

Bussotti F., Strasser R.J., Schaub M. 2007b. Photosynthetic behavior of woody species under high ozone exposure probed with the JIP-test: A review. Environmental Pollution, 147:430-437.

Calatayud A., Barreno E. 2001. Chlorophyll a fluorescence, antioxidant enzymes and lipid peroxidation in tomato in response to ozone and benomyl. Environment Pollution, 115:283-289.

Calvo E., Martin C., Sanz M.J. 2007. Ozone sensitivity differences in five tomato cultivars: visible injury and effects on biomass and fruits. Water Air Soil Pollution, 186:167-181.

Clark A.J., Landolt W., Bucher J.B., Strasser R.J. 2000. Beech (Fagus sylvatica) response to ozone exposure assessed with a chlorophyll a fluorescence performance index. Environmental Pollution, 109:501-507.

Danielsson H., Phil-Karlsson G, Karlsson P.E., Pleijel H. 2003. Ozone uptake modelling and flux-response relationships - an assessment of ozone-induced yield loss in spring wheat. Atmospheric Environment, $37: 475-485$.

Degl'Innocenti E., Guidi L., Soldatini G.F. 2002. Effect of chronic $\mathrm{O}_{3}$ fumigation on the activity of some Calvin cycle enzymes in two poplar clones. Photosynthetica, 40:121-126.

Drogoudi P.D., Ashmore M. 2000. Does elevated ozone have differing effects in flowering and deblossomed strawberry? New Phytologist, 147:561-569.

EEA (European Environment Agency) 2006. Air pollution by ozone in Europe in summer 2005. Topic Report.

EEA (European Environment Agency) 2007. Air pollution in Europe 1990-2004. EEA Report No 2/2007.

Emberson L., Wieser G., Ashmore M. 2000. Modelling of stomatal conductance and ozone flux of Norway spruce: comparison with field data. Environmental Pollution, 109:393-402.

Emberson L.D., Ashmore M.R., Murray F., Kuylenstierna J.C.I., Percy K.E., Izuta T., Zheng Y., Shimizu H., Sheu B.H., Liu C.P. 2001. Impacts of air pollutants on vegetation in developing countries. Water Air Soil Pollution, 130:107-118.

Fagnano M., Merola G. 2007. Ozone and water stress: effects on the behavior of two white clover biotypes. Italian Journal of Agronomy, 2:3-12.
Fuhrer J., Skärby L., Ashmore M. 1997. Critical levels for ozone effects on vegetation in Europe. Environmental Pollution, 97:91-106.

Gerosa G., Marzuoli R., Desotgiu R., Bussotti F., Ballarin-Denti A. 2007. Visible leaf injury in young trees of Fagus sylvatica L. and Quercus robur L. in relation to ozone uptake and ozone exposure. An Open-Top Chambers experiment in South Alpine Environmental conditions. Environmental Pollution, 152:274-284.

Gerosa G., Marzuoli R., Rossini M., Panigada C., Meroni M., Colombo R., Faoro F., Iriti M. (submitted). Leaf damages, photosynthetic efficiency and productivity of bean plants exposed to ozone: a flux-based study. Environmental Pollution.

Gimeno B.S., Bermejo V., Reinert R.A., Zheng Y. 1999. Adverse effects of ambient ozone on watermelon yield and physiology at a rural site in Eastern Spain. New Phytologist, 144:245-260.

Heath R.L. 1994. Possible mechanisms for the inhibition of photosynthesis by ozone. Photosynthesis Research, 39:439-451.

Jarvis P.G. 1976. The interpretation of the variations in leaf water potential and stomatal conductance found in canopies in the field. Philosophical Transactions of the Royal Society of London. Series B, Biological Sciences, 273:593-610.

Kangasjarvi J., Talvinen J., Utriainen M., Karjalainen R. 1994. Plant defence system induced by ozone. Plant Cell Environment, 17:783-794

Kärenlampi L., Skärby L. 1996. Critical Levels for Ozone in Europe: Testing and Finalizing the Concepts. UN/ECE Workshop Report: UN/ECE Convention on Long-Range Transboundary Air Pollution Workshop in Kuopio, Finland, 15-17 April, 1996. University of Kuopio, Dept. of Ecology and Environmental Science.

Karlsson P.E., Pleijel H., Pihl-Karlsson G., Medin E.L., Skärby L. 2000. Simulations of stomatal conductance and ozone uptake to Norway spruce saplings in opentop chambers. Environmental Pollution, 109:443-451.

Khan M.R., Khan M.R. 1999. Effects of intermittent ozone exposures on powdery mildew of cucumber. Environment Experimental Botany, 42:163-171.

Langebartels C., Wohlgemuth H., Kschieschan S. 2002. Oxidative burst and cell death in ozone-exposed plants. Plant Physiology Biochemestry, 40:567-575.

Maggio A., De Pascale S., Fagnano M., Barbieri G. 2007. Can salt stress-induced physiological responses protect tomato crops from ozone damages in Mediterranean environments? European Journal of Agronomy, 26:454-461.

Mauzerall D.L., Wang X. 2001. Protecting agricultural crops from the effects of tropospheric ozone exposure: Reconciling Science and Standard Setting in the United States, Europe, and Asia. Annual Review of Energy and the Environment, 26:237-268.

Musselman R.C., Massman W.J. 1999. Ozone flux to vegetation and its relationship to plant response and am- 
bient air quality standards. Atmospheric Environment, 33:65-73.

Panek J.A., Goldstein A.H. 2001. Response of stomatal conductance to drought in ponderosa pine: implications for carbon and ozone uptake. Tree Physiology, 21:337-344.

Paoletti E. 2006. Impact of ozone on Mediterranean forests: A review. Environmental Pollution, 144:463474.

Pleijel H., Danielsson H., Emberson L., Ashmore M., Mills G. 2007. Ozone risk assessment for agricultural crops in Europe: Further development of stomatal flux and flux-response relationships for European wheat and potato. Atmospheric Environment, 41:3022-3040.

Pleijel H., Danielsson H., Vandermeiren K., Blum C., Colls J., Ojanperä K. 2002. Stomatal conductance and ozone exposure in relation to potato tuber yield results from the European CHIP programme. European Journal of Agronomy, 17:303-317.

Rabotti G., Ballarin-Denti A. 1998. Biochemical responses to abiotic stress in Beech (Fagus sylvatica L.) leaves. Chemosphere, 36:871-875.

Ranieri A., D’Urso G., Nali C., Lorenzini G., Soldatini G.F. 1996. Ozone stimulates apoplastic antioxidant systems in pumpkin leaves. Physiologia Plantarum, 97:381-387.

Schenone G., Botteschi G., Fumagalli I., Montinaro F. 1992. Effects of Ambient Air Pollution in Open-Top Chambers on Bean (Phaseolus vulgaris L.). I. Effects on growth and yield. New Phytologist, 122:689-697.

Schraudner M., Langebartels C., Sandermann H. 1997. Changes in the biochemical status of plant cells induced by the environmental pollutant ozone. Physiologia Plantarum, 100:274-280.

Sobeih W.Y., Dodd I.C., Bacon M.A., Grierson D., Davies W.J. 2004. Long-distance signals regulating stomatal conductance and leaf growth in tomato ( $L y$ copersicon esculentum) plants subjected to partial root-zone drying. Journal of Experimental Botany, 55:2353-2363.

Stewart C.A., Black V.J., Black C.R., Roberts J.A. 1996. Direct effects of ozone on the reproductive development of Brassica species. Journal of Plant Physiology, 148:172-178.

Strasser A., Tsimilli-Michael M., Srivastava A. 2004. Analysis of the fluorescence transient. In: Papageorgiou G., Govindjee (eds): Chlorophyll Fluorescence: A Signature of Photosynthesis, 321-362. Kluwer Academic Publishers, Netherlands.

Strasser R.J., Srivastava A., Tsimilli-Michael M. 2000. The fluorescence transient as a tool to characterize and screen photosynthetic samples. Probing Photosynthesis: Mechanisms, Regulation and Adaptation, 445-483.

Thom A.S. 1975. Momentum, mass and heat exchange of plant communities. Vegetation and the Atmosphere, 1:57-109.

UN/ECE 2004. Revised manual on methodologies and criteria for mapping critical levels/loads and geographical areas where they are exceeded, Chapter 3: Mapping Critical Levels for Vegetation. UNECE Convention on Long-Range Transboundary Air Pollution. Umweltbundesamt, Berlin.

Unsworth M.H., Heagle A.S., Heck W.W. 1984. Gas exchange in open-top field chambers. I: Measurement and analysis of atmospheric resistances to gas exchange. Atmospheric Environment, 18:373-380.

Vingarzan R. 2004. A review of surface ozone background levels and trends. Atmospheric Environment, 38:3431-3442.

Younglove T., McCool P.M., Musselman R.C., Kahl M.E. 1994. Growth-stage dependent crop yield response to ozone exposure. Environmental Pollution, 86:287295. 